\title{
Cardiovascular Comorbidities for Prediction of Progression-Free Survival in Patients with Metastatic Renal Cell Carcinoma Treated with Sorafenib
}

\author{
Sebastian Szmit ${ }^{a}$ b Magdalena Zaborowska ${ }^{a}$ Anna Waśko-Grabowska ${ }^{a}$ \\ Jakub Żołnierek $^{\mathrm{a}}$ Paweł Nurzyński ${ }^{\mathrm{a}} \quad$ Krzysztof J. Filipiak $^{\mathrm{b}} \quad$ Grzegorz Opolski $^{\mathrm{b}}$ \\ Cezary Szczylik ${ }^{a}$

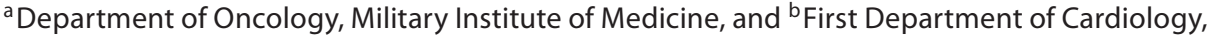 \\ Medical University of Warsaw, Warsaw, Poland
}

\section{Key Words}

Hypertension - Renal cell carcinoma - Sorafenib •

Progression-free survival

\begin{abstract}
Background/Aims: The purpose of the present study was to determine the relationship between iatrogenic arterial hypertension or baseline cardiovascular comorbidities and outcomes in metastatic renal cell cancer (mRCC) patients treated with sorafenib. Methods: The study included 148 mRCC patients treated with sorafenib, 63 patients (43\%) had preexisting hypertension, 18 patients (12\%) coronary artery disease, and 15 patients (10\%) mild heart failure. Resting blood pressure (BP) was monitored by clinic and home measurements. Sorafenib-induced hypertension was defined as systolic BP $\geq 140$ and/or diastolic BP $\geq 90 \mathrm{~mm} \mathrm{Hg}$ during the first month of treatment. Results: Preexisting cardiovascular comorbidities were not associated with worsening prognosis of patients with mRCC treated with sorafenib. During the first month of treatment, sorafenib-induced hypertension was diagnosed in 76 patients (51.4\%), and these patients had a significantly longer PFS ( $p<0.00001)$ and a significantly
\end{abstract}

lower overall mortality risk $(p=0.038)$. Patients with preexisting and sorafenib-induced hypertension had the longest PFS ( $p<0.00001)$. Conclusions: Sorafenib-induced hypertension is a positive predictive factor in $\mathrm{mRCC}$ patients treated with sorafenib, especially in patients with a history of hypertension.

Copyright $\odot 2012$ S. Karger AG, Basel

\section{Introduction}

There are some initial data available that suggest that hypertension induced by sunitinib, bevacizumab or sorafenib correlates with the effectiveness of the treatment of metastatic renal cell cancer (mRCC) $[1,2]$. In the case of sunitinib, this effect has already been thoroughly analyzed [3-6], and it has been shown that a significant risk of the development of heart failure exists during treatment with sunitinib. This risk may be associated with iatrogenic hypertension [7]. In addition, a history of arterial hypertension or coronary heart disease was positively correlated with the risk of heart failure in patients treated with sunitinib [8]. Similar data are not available

\section{KARGER \\ Fax +4161306 1234 \\ E-Mail karger@karger.ch}

www.karger.com
(C) 2012 S. Karger AG, Basel

$1420-4096 / 12 / 0356-0468 \$ 38.00 / 0$

Accessible online at: www.karger.com/kbr
Sebastian Szmit, MD, PhD

Department of Oncology, Military Institute of Medicine Szaserow Street 128

PL-00-909 Warsaw (Poland)

Tel. +48 2261030 98, E-Mail s.szmit@gmail.com 
for sorafenib. The purpose of the present study was to determine the relationship between iatrogenic arterial hypertension or baseline cardiovascular comorbidities and outcomes in mRCC patients treated with sorafenib.

\section{Materials and Methods}

\section{Patients}

Patients with mRCC with prior nephrectomy, aged 18 years or older, treated with sorafenib, were included in the study. Required ECOG (Eastern Cooperative Oncology Group) performance status was 0,1 or 2 . Exclusion criteria included: total serum bilirubin $>2 \times$ the upper limit of normal (ULN), serum transaminases $>5 \times \mathrm{ULN}$, serum creatinine $>2 \times \mathrm{ULN}$, absolute neutrophil count $<1,000 / \mathrm{mm}^{3}$, platelets $<75,000 / \mathrm{mm}^{3}$, and hemoglobin $<8.0 \mathrm{~g} / \mathrm{dl}$.

Patients with cardiovascular comorbidities were eligible for treatment, except for patients with heart failure of NYHA class III or IV or patients with coronary disease with CCS class II-IV symptoms. The diagnosis of coronary heart disease was accepted if established on the basis of coronarography or noninvasive imaging examinations. Mild heart failure was diagnosed if NYHA class I or II exertional dyspnea symptoms were present in a patient with abnormal echocardiographic examination results (range of ejection fraction between 40 and 50\%). Arterial hypertension was diagnosed in accordance with the current guidelines. Blood pressure (BP) values $\geq 140 / 90 \mathrm{~mm} \mathrm{Hg}$ were recognized as hypertension. Baseline arterial hypertension had to be carefully controlled with antihypertensive drugs.

The study complied with the provisions of the Declaration of Helsinki, Good Clinical Practice Guidelines, and local laws and regulations. The study was approved by a local ethics committee.

\section{Assessment of Clinical Benefits and Outcomes}

Primary criterion of evaluation of clinical benefits and outcomes was the progression-free survival (PFS), secondary criterion was best radiological response, third - risk of cardiovascular complications.

PFS was the time between the initiation of sorafenib treatment and the radiological progression of cancer, unacceptable toxicity, death or clinical status deterioration precluding further treatment (ECOG-4). Follow-up CT scans were obtained every 2 months during treatment. Best radiological response was qualified as complete/partial response, stable disease or progression, comparing following CT scans according to the RECIST criteria. Patients were monitored for toxicity according to Common Criteria for Adverse Events (CTCAE, v3.0).

The risk of cardiovascular complications were defined as the likelihood of occurrence of cardiac death, heart failure symptoms of at least NYHA class III, hypertensive crisis, myocardial infarction, stroke, or thromboembolic event.

\section{Assessment of Iatrogenic Arterial Hypertension}

Patients initiating sorafenib treatment had adequate BP control, i.e. BP values <140/90 mm Hg. Resting BP was closely monitored during the first 4 weeks of sorafenib treatment: clinic measurements were done on days 14 and 28, and home measurements recommended for every day. During the clinic visit, BP was mea- sured twice by the nurses. All patients measured their BP three times a day at rest.

Sorafenib-induced hypertension was diagnosed if all values of clinic measurement and the mean BP of home measurements were systolic $\mathrm{BP} \geq 140$ and/or diastolic $\mathrm{BP} \geq 90 \mathrm{~mm} \mathrm{Hg}$. This algorithm was associated with a very low risk of false-positive diagnosis.

\section{Statistical Analyses}

All statistical analyses were performed using STATISTICA 7.0 software. PFS was determined using the Kaplan-Meier survival analysis method and was compared using a log-rank test. Comparisons between treatment groups were performed using $\chi^{2}$ tests for differences in the incidence of disease progression, stable disease or partial remission, and the statistical significance of the differences was determined using the Yates two-sided test at the $5 \%$ significance level. Risks of occurrence of cardiovascular events were expressed as odds ratios (OR) and 95\% confidence intervals (CI).

\section{Results}

\section{Patient Population and Effect of Treatment with Sorafenib}

The retrospective analysis included 148 patients with mRCC with prior nephrectomy. Detailed patient characteristics are presented in table 1 . None of the patients had been previously treated with angiogenesis inhibitors. In all patients, sorafenib was given at a dose of $400 \mathrm{mg}$ twice daily. The follow-up was initiated on March 15, 2004 and finished on December 31, 2010.

A high percentage of the 148 patients had cardiovascular comorbidities (table 1). The following disorders were diagnosed at baseline: coronary disease in 18 patients $(12 \%)$ and hypertension in 63 patients (43\%). Hypertension was diagnosed at least 3 months before the initiation of sorafenib treatment and was optimally controlled with at least one antihypertensive drug. Additionally, in 15 patients (10\%), mild heart failure was diagnosed: 7 patients with post-myocardial heart dysfunction and 8 patients with mitral valve insufficiency with coexisting persistent atrial fibrillation.

During sorafenib treatment, the following were noted as the best radiological responses: partial remission - 18 patients (12\%), stable disease - 102 patients (69\%), and primary resistance, i.e. progression on the first follow-up CT scan (primary progressive disease) - 28 patients (19\%).

The median PFS for the whole patient population was 202 days. Radiological progression according to RECIST was diagnosed in 116 patients, and 9 patients discontinued their treatment due to clinical progression (clinical status deterioration precluding further treatment, i.e. ECOG-4). Another 16 patients (10.8\%) died during 
Table 1. Baseline characteristics of 148 patients with mRCC treated with sorafenib

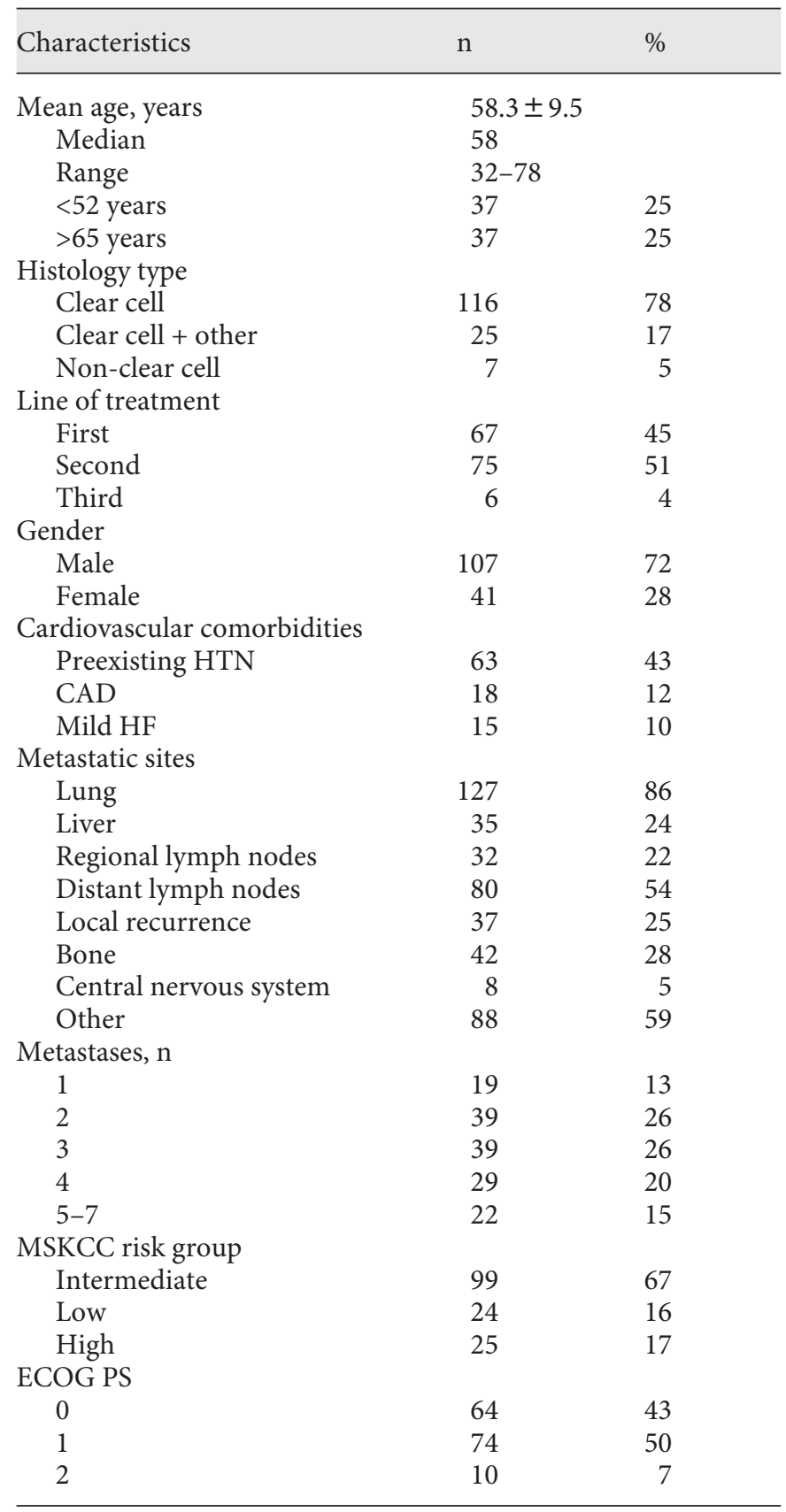

ECOG = Eastern Cooperative Oncology Group; MSKCC = Memorial Sloan-Kettering Cancer Center; PS = performance status; $\mathrm{HTN}=$ hypertension; $\mathrm{CAD}=$ coronary artery disease; $\mathrm{HF}=$ heart failure. sorafenib treatment before radiological progression was found. In 7 patients, no disease progression was observed when the follow-up ended (censored cases).

\section{Effects of Preexisting Cardiovascular Comorbidities on PFS}

In the study population of mRCC patients, 63 patients (43\%) had hypertension that was diagnosed before sorafenib treatment. This patient group had a significantly longer PFS compared with patients without a history of arterial hypertension (HR $=0.67$ (95\% CI 0.48-0.94); $\mathrm{p}=$ 0.02 ) (fig. 1). In addition, this patient group had primary disease progression relatively rarely as a treatment response (table 2) - only 9 cases among 63 patients versus 19 cases among 85 patients without hypertension $(\mathrm{OR}=$ 0.58 (95\% CI 0.21-1.60); $\mathrm{p}=0.29$ ).

Patients with mRCC and with coexisting coronary heart disease or mild heart failure had the same level of PFS as patients without these diseases ( $\mathrm{HR}=0.987(95 \%$ CI 0.967-1.007); $\mathrm{p}=0.18$ ) (fig. 2).

The overall mortality risk during active sorafenib treatment (table 3) was not significantly increased due to a history of hypertension (OR = 1.73 (95\% CI 0.51-5.88); $\mathrm{p}=0.38)$, coronary disease and mild heart failure $(\mathrm{OR}=$ 0.99 (95\% CI 0.93-1.05); $\mathrm{p}=0.78$ ).

\section{Effects of Iatrogenic Hypertension on PFS}

Iatrogenic hypertension was diagnosed in 76 patients (51.4\%) during the first month of treatment with sorafenib. As from the moment of diagnosis, all of these patients received empirical antihypertensive treatment, in line with obligatory guidelines. We tried to use the following algorithm: first drug: angiotensin-converting enzyme inhibitor, second drug: thiazide diuretic, third drug: $\beta$ blocker, and when it was necessary, fourth drug: calciumchannel blocker. All patients had good control of their BP after starting antihypertensive treatment.

Patients with hypertension induced by sorafenib had a significantly longer PFS (HR $=0.78$ (95\% CI 0.72-0.85); $\mathrm{p}<0.00001$ ) (fig. 3).

Patients with iatrogenic hypertension had significantly better radiological responses to treatment $(\mathrm{p}<0.0001)$ (table 2). In particular, stable disease occurred significantly more often as the best response: 63 cases among the patients with iatrogenic hypertension versus 39 cases among the patients without hypertension (table 2). In addition, this group of patients had a significantly less frequent primary disease progression as a treatment response (table 2): only 4 of 76 patients with iatrogenic hypertension versus 24 of 72 patients without iatrogenic 


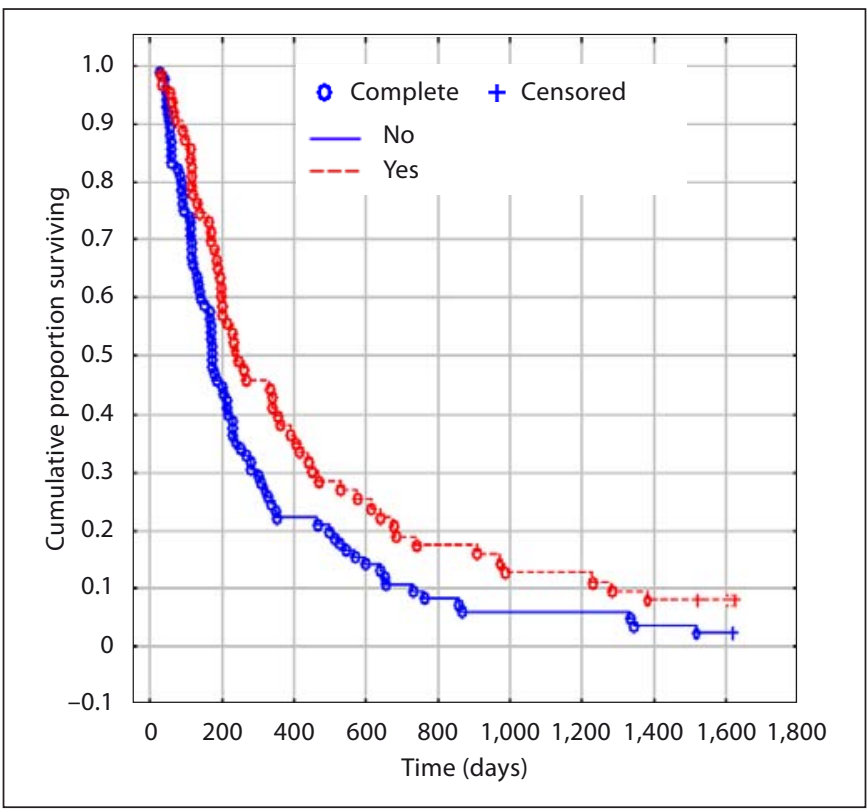

Fig. 1. PFS in mRCC patients treated with sorafenib who did or did not have preexisting hypertension. OR $=0.67$ (95\% CI $0.48-$ $0.94 ; \mathrm{p}=0.02)$.

\begin{tabular}{lll}
\hline Subgroup & $\begin{array}{l}\text { With preexisting } \\
\text { hypertension }(\mathrm{n}=63)\end{array}$ & $\begin{array}{l}\text { Without preexisting } \\
\text { hypertension }(\mathrm{n}=85)\end{array}$ \\
\hline Median, months & 8.02 & 5.72 \\
\hline
\end{tabular}

hypertension experience primary disease progression $(\mathrm{OR}=0.58$ (95\% CI 0.43-0.78); $\mathrm{p}=0.0004)$.

The overall mortality risk during treatment with sorafenib was significantly reduced in patients with iatrogenic arterial hypertension (OR $=0.73$ (95\% CI $0.54-$ $0.98) ; \mathrm{p}=0.038$ ). Notably, patients with preexisting and sorafenib-induced hypertension had the longest PFS ( $\mathrm{p}<$ 0.00001) compared either with patients with only sorafenib-induced hypertension or with patients who were normotensive all the time during treatment with sorafenib (fig. 4).

In a subgroup of patients with preexisting and sorafenib-induced hypertension, only 1 patient had primary disease progression as a treatment response (table 2); nobody died during active sorafenib treatment (table 3).

\section{Cardiovascular Adverse Events}

Antihypertensive treatment was empirical. After the first month of sorafenib treatment, patients had effective-

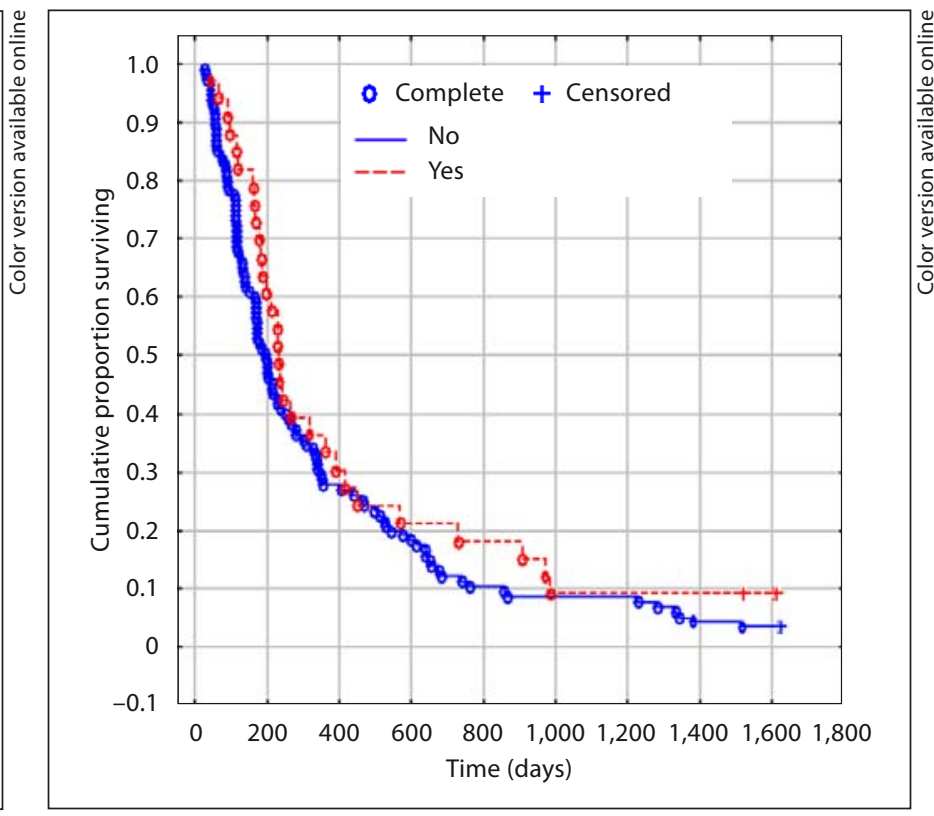

Fig. 2. PFS in mRCC patients treated with sorafenib who did or did not have CAD or mild HF. OR = 0.987 (95\% CI 0.967-1.007; $\mathrm{p}=0.18)$.

\begin{tabular}{lll}
\hline Subgroup & $\begin{array}{l}\text { With CAD or } \\
\text { mild HF }(\mathrm{n}=33)\end{array}$ & $\begin{array}{l}\text { Without CAD } \\
\text { or mild HF }(\mathrm{n}=115)\end{array}$ \\
\hline Median, months & 7.68 & 6.52 \\
\hline
\end{tabular}

ly controlled BP with reached goals of $<140 / 90 \mathrm{~mm} \mathrm{Hg}$ (clinic measurements) and $<135 / 85 \mathrm{~mm} \mathrm{Hg}$ (home monitoring). Regarding cardiac safety, three episodes of heart failure exacerbation with NYHA class III symptoms occurred during treatment with sorafenib; in 2 cases, these episodes were transient and could be effectively controlled with pharmacological treatment. In 1 case, the episode occurred at the time at which radiological progression was diagnosed. Moreover, three episodes of the central nervous system (CNS) ischemia occurred: 2 strokes and 1 transient ischemic attack (TIA). Two episodes of peripheral vein thrombosis occurred. One myocardial infarction was diagnosed. There were no cardiac deaths or hypertensive crisis episodes.

The risk of all major cardiovascular events (table 3) was not significantly increased due to a history of hypertension $(\mathrm{OR}=0.57$ (95\% CI 0.14-2.42); $\mathrm{p}=0.45)$, coronary disease or mild heart failure $(\mathrm{OR}=0.97$ (95\% CI 0.90 1.04); $\mathrm{p}=0.42$ ). 


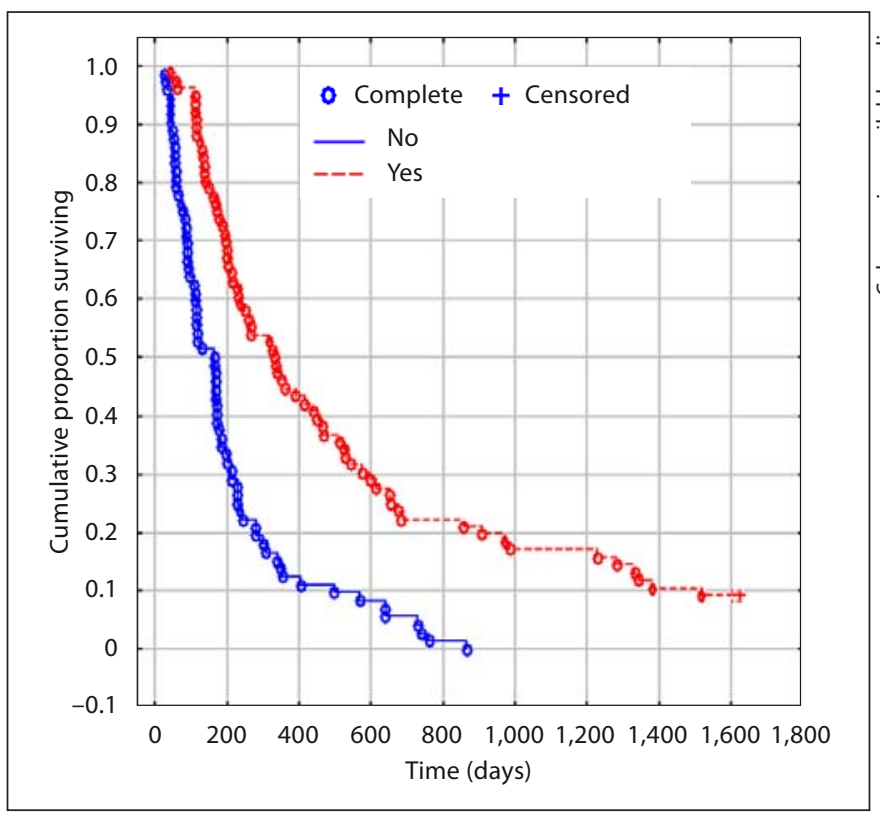

Fig. 3. PFS in mRCC patients who did or did not develop early iatrogenic hypertension related to treatment with sorafenib. $\mathrm{OR}=0.78$ (95\% CI 0.72-0.85; $\mathrm{p}<0.00001)$.

\begin{tabular}{lll}
\hline Subgroup & $\begin{array}{l}\text { With sorafenib-induced } \\
\text { hypertension }(\mathrm{n}=76)\end{array}$ & $\begin{array}{l}\text { Without sorafenib-induced } \\
\text { hypertension }(\mathrm{n}=72)\end{array}$ \\
\hline Median, months & 11.13 & 5.5 \\
\hline
\end{tabular}

Despite such frequent sorafenib-induced hypertension, other cardiovascular complications rarely occurred. Indeed, all CNS ischemia episodes (3 cases) and myocardial infarctions occurred in patients with sorafenib-induced hypertension (table 3). Nevertheless, the risk of all cardiovascular events for patients with iatrogenic hypertension was not significantly increased in comparison with the risk for patients without hypertension $(\mathrm{OR}=1.05$ (95\% CI 0.74-1.47); $\mathrm{p}=0.79$ ). Cardiovascular complications were incidental in patients with preexisting and sorafenib-induced hypertension (table 3).

The limitation of the study is that the analyses of outcomes were not corrected for other prognostic factors like ECOG performance status and Memorial Sloan-Kettering Cancer Center (MSKCC) criteria. The predictive value of hypertension related to sorafenib needs further investigation and validation.

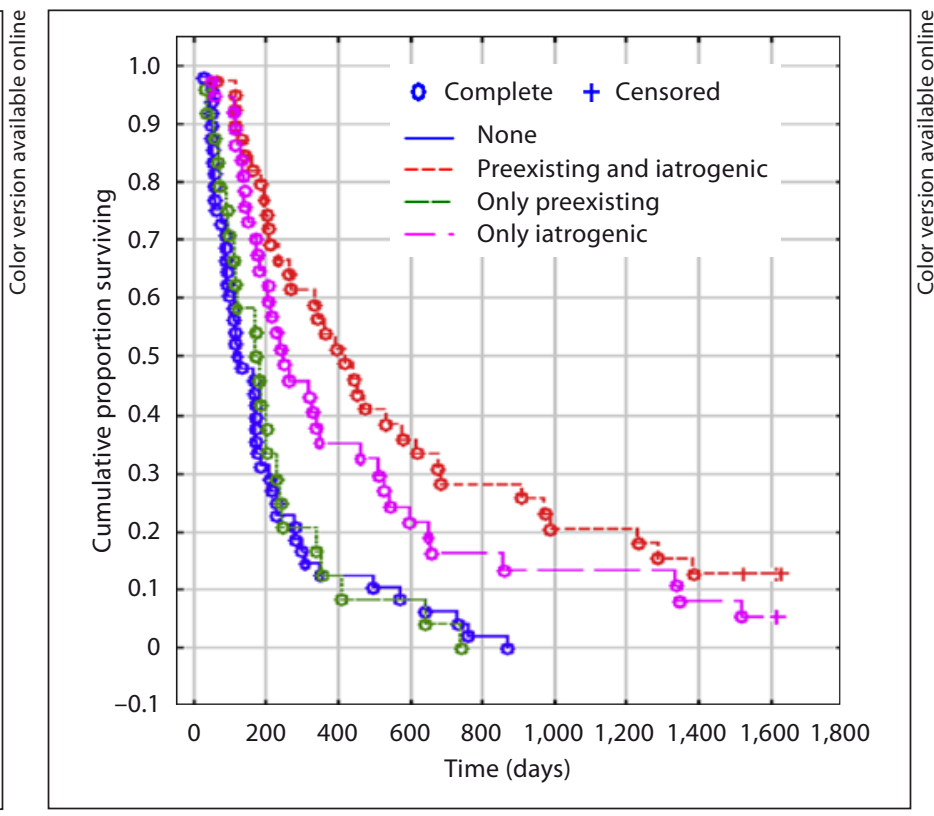

Fig. 4. PFS in mRCC patients: analysis-dependent on whether the patients had preexisting hypertension and developed iatrogenic sorafenib-induced hypertension $(\mathrm{p}<0.00001)$.

\begin{tabular}{lllll}
\hline Subgroup & \multicolumn{4}{l}{ Status of hypertension } \\
\cline { 2 - 5 } & $\begin{array}{l}\text { preexisting and } \\
\text { sorafenib- } \\
\text { induced }(\mathrm{n}=39)\end{array}$ & $\begin{array}{l}\text { only } \\
\text { sorafenib- } \\
\text { induced }(\mathrm{n}=37)\end{array}$ & $\begin{array}{l}\text { only } \\
\text { preexisting } \\
(\mathrm{n}=24)\end{array}$ & $\begin{array}{l}\text { none } \\
(\mathrm{n}=48)\end{array}$ \\
\hline Median, months & 13.45 & 8.1 & 5.6 & 3.93 \\
\hline
\end{tabular}

\section{Discussion}

Sorafenib is an oral multikinase inhibitor that blocks, among other pathways, the vascular endothelial growth factor (VEGF)-related pathway. It has been shown that, in mRCC patients, sorafenib treatment significantly prolongs PFS [9]. It is also known that angiogenesis inhibitors frequently cause hypertension, proteinuria, thrombosis and bleeding [10]. Therefore, a question arises as to whether the risk of such events potentially allows therapy of patients with cardiovascular comorbidities. This question becomes even more important in the case of sorafenib, which, in addition to the VEGF pathway, effectively blocks PDGF- and Raf-related pathways, which may be of importance to the heart and blood vessels.

In cancer patients $\geq 70$ years old, on average at least three comorbidities are present; these comorbidities very often include hypertension, coronary disease or heart 
Table 2. Number of patients with best tumor response (according to RECIST) during treatment with sorafenib based on preexisting or sorafenib-induced hypertension

\begin{tabular}{lrrrr}
\hline Subgroup & PR & SD & PD & p value \\
\hline Preexisting hypertension & & & & \\
$\quad$ Yes $(\mathrm{n}=63)$ & 6 & 48 & 9 & 0.2574 \\
$\quad$ No $(\mathrm{n}=85)$ & 12 & 54 & 19 & \\
Sorafenib-induced hypertension & & & & \\
$\quad$ Yes $(\mathrm{n}=76)$ & 9 & 63 & 4 & $<0.0001$ \\
$\quad$ No $(\mathrm{n}=72)$ & 9 & 39 & 24 & \\
Preexisting and sorafenib-induced hypertension & & \\
$\quad$ Yes $(\mathrm{n}=39)$ & 6 & 32 & 1 & 0.0318 \\
$\quad$ No $(\mathrm{n}=109)$ & 12 & 70 & 27 & \\
\hline
\end{tabular}

$\mathrm{PR}=$ Partial remission; $\mathrm{SD}=$ stable disease $\mathrm{PD}=$ primary progressive disease.

Table 3. Cardiovascular events and mortality during active sorafenib treatment in 148 patients with mRCC

\begin{tabular}{|c|c|c|c|c|c|}
\hline $\begin{array}{l}\text { Subgroups related to } \\
\text { presence of cardiovascular } \\
\text { comorbidities }\end{array}$ & $\begin{array}{l}\text { Death } \\
\text { before } \\
\text { PD }\end{array}$ & $\begin{array}{l}\text { Stroke/ } \\
\text { TIA }\end{array}$ & $\begin{array}{l}\text { HF } \\
\text { (NYHA } \\
\text { III) }\end{array}$ & MI & $\begin{array}{l}\text { Throm- } \\
\text { bosis }\end{array}$ \\
\hline \multicolumn{6}{|l|}{ Preexisting hypertension } \\
\hline Yes $(n=63)$ & 5 & 1 & 1 & 1 & 2 \\
\hline No $(\mathrm{n}=85)$ & 11 & 2 & 2 & 0 & 0 \\
\hline \multicolumn{6}{|l|}{$\mathrm{CAD}+$ mild HF } \\
\hline Yes $(n=33)$ & 4 & 0 & 2 & 0 & 1 \\
\hline No $(\mathrm{n}=115)$ & 12 & 3 & 1 & 1 & 1 \\
\hline \multicolumn{6}{|c|}{ Sorafenib-induced hypertension } \\
\hline Yes $(n=76)$ & 4 & 3 & 1 & 1 & 0 \\
\hline No $(\mathrm{n}=72)$ & 12 & 0 & 2 & 0 & 2 \\
\hline \multicolumn{6}{|c|}{ Preexisting and sorafenib-induced hypertension } \\
\hline Yes $(\mathrm{n}=39)$ & 0 & 1 & 0 & 1 & 0 \\
\hline No $(n=109)$ & 16 & 2 & 3 & 0 & 2 \\
\hline \multicolumn{6}{|l|}{ All patients with } \\
\hline serious events & 16 & 3 & 3 & 1 & 2 \\
\hline
\end{tabular}

The table includes the incidence of serious events in relationship to cardiovascular comorbidities.

$\mathrm{PD}=$ Progressive disease; TIA = transient ischemic attack; $\mathrm{HF}=$ heart failure; $\mathrm{MI}=$ myocardial infarction $; \mathrm{CAD}=$ coronary artery disease; NYHA = New York Heart Association.

failure [11]. Every fourth patient with a newly diagnosed renal tumor is $>74$ years old [12].

As shown by cardiologic studies: (1) The probability of heart failure increases proportionally with the patient's age. In our population of mRCC patients, every fourth patient (25\%) was $>65$ years old. (2) The higher incidence of cardiac disorders in men is associated with more frequent coronary atherosclerosis at a younger age, by about 10 years [13]. In our population, men constituted a definite majority - 107 persons (72\%). (3) Hypertension is one of the most significant risk factors for coronary disease and, thus, for heart failure [14]. Almost half (43\%) of the patients in our population had preexisting hypertension before starting sorafenib treatment.

In our study, we took into account all disorders associated with a significant risk for the development of symptomatic heart failure and mild heart failure. Despite the above finding, cardiovascular complications were rare. Coronary disease and mild heart failure had no negative effects on PFS, and the presence of hypertension actually had a positive effect on PFS. Therefore, we may say that this is a paradox of cardio-oncology, but we should notice that it may be related to our close cardiologic monitoring and efficient intervention in patients with cardiovascular comorbidities. It is still unknown whether any genetic predisposition to cardiovascular side effects has significance in patients receiving angiogenesis inhibitors.

The issues of our retrospective analysis must be analyzed in several aspects. It remains to be determined whether sorafenib is less cardiotoxic than sunitinib. Unfortunately, there has been no unequivocal evidence for this theory because such precise cardiac follow-up data were not available in sorafenib studies, as in the case of sunitinib. A phase I open-label study reported that sorafenib treatment did not induce significant echocardiographic and electrocardiographic changes in patients with advanced cancer [15]. The available data suggest that a history of arterial hypertension and coronary heart disease are risk factors for cardiovascular events during sunitinib treatment in univariate analysis $[16,17]$. We did not observe a similar correlation in our study with sorafenib.

Moreover, there are data that sorafenib can be effectively and safely used in patients with contractile dysfunctions of the heart [18], even after an episode of severe sunitinib-induced heart failure [19]. Our study suggests that the presence of mild heart failure or coronary heart disease had no negative effect on PFS, mortality or the risk of cardiovascular events during treatment with sorafenib. Our results are similar to the findings of Schmidinger et al. [20] indicating that tyrosine kinase inhibitors sorafenib and sunitinib may be effective and safe enough to be used in patients with lifestyle and cardiometabolic risk factors. Moreover, in such a defined population, there is no difference in survival between patients with cardiac events and others. 
As suggested by epidemiological studies, the risk of renal cancer is significantly higher in patients with arterial hypertension [21]. Therefore, it should not be surprising that as many as $43 \%$ of the patients in our population had preexisting hypertension before the start of treatment. Unfortunately, this fact may constitute a serious limitation in determining eligibility for treatment with angiogenesis inhibitors because the risk of hypertensive crisis or heart failure increases. In the observation by Telli et al. [17], a history of hypertension was present in $67 \%$ of patients determined to be eligible for sunitinib treatment, which resulted in heart failure in as many as $15 \%$ of the patients. It is important for our results that baseline hypertension not only did not increase the risk of major cardiovascular events (table 3 ) but also identified the patients with significantly longer PFS (fig. 1). For comparison, Rini et al. [5] found that patients treated with sunitinib with a history of hypertension have a significantly longer overall survival (median 31.8 vs. 21.4 months; $p<0.001$ ) without differences in PFS, but Szmit et al. [6] did not notice any differences in survival related to sunitinib between patients with and without preexisting hypertension.

Our study demonstrates an association between sorafenib-induced hypertension and PFS prolongation (fig. 3) as well as an increased incidence of better radiological response to treatment (table 2). Overall mortality during treatment with sorafenib was also significantly lower in patients with iatrogenic arterial hypertension. Cardiovascular complications during sorafenib treatment were rare (table 3 ) and were not significantly correlated with iatrogenic hypertension. However, it should be noted that all episodes of CNS ischemia and myocardial infarction occurred in the patients with sorafenibinduced hypertension. Nevertheless, the results of our study support that the clinical benefit of sorafenib is higher than the cardiac risk. Iatrogenic arterial hypertension occurring already in the first month of treatment is a good prognostic factor for cancer. Similarly, this finding indicates the necessity of ensuring optimal cardiac control of patients. Further studies are necessary to demonstrate the effectiveness of antihypertensive treatment for iatrogenic hypertension and its effect on the reduction of cardiovascular events.

Observations suggest that arterial hypertension of grade 3 or 4, according to CTCAE, may occur more often during treatment with sunitinib than with sorafenib: 6.8\% (95\% CI 5.3-8.8\%) for sunitinib [22] and 5.7\% (2.5$12.6 \%)$ for sorafenib [23]. Khakoo et al. [7] found that it may be the cause of severe cardiovascular events during treatment with sunitinib. In this aspect our study seems to be very interesting because patients with preexisting and iatrogenic hypertension (grade 3 according to CTCAE) have the longest PFS with an insignificant risk of cardiovascular complications. It is in agreement with observations of Bamias et al. [24] suggesting that there is inversely a proportion between the incidence of iatrogenic hypertension and risk of cardiovascular events in patients treated with angiogenesis inhibitors. This relationship results from carefully monitoring $\mathrm{BP}$ thanks to home measurements and using 24-hour automatic monitoring in specific situations.

The available data indicate that the increase in $\mathrm{BP}$ induced by sorafenib occurs on the first day of treatment; it is difficult to predict the amplitude of this increase because it does not correlate with the patient's age, weight, race, sex or baseline BP [25]. Some authors suggest that sorafenib-dependent pressure increases are caused directly by the blockade of the VEGF pathway, others postulate that this is a secondary effect involving epithelium dysfunction [26]. In a pilot study, patients receiving sorafenib at a dose of $400 \mathrm{mg}$ twice daily had a mean increase of systolic and diastolic BP of 10/7 $\mathrm{mm} \mathrm{Hg}$, and this was a positive predictive factor [27]. The results of our study correlate with this finding: in patients with sorafenib-induced hypertension, PFS is significantly longer, mortality was significantly lower, and the risk of primary progression was significantly lower. Moreover, patients with preexisting hypertension seem to be good candidates for treatment with sorafenib, because if they experience early iatrogenic hypertension induced by sorafenib, they have the most favorable outcome. The retrospective nature of our work greatly limits the importance of these conclusions. All findings require evaluation in prospective studies.

The results of our study are in agreement with the findings of other observations demonstrating the positive prognosis of patients who experienced hypertension under treatment with different angiogenesis inhibitors. It was reported that the significantly lower relative risk of death and relative lower risk of progression disease characterized patients with increased diastolic BP $\geq 90 \mathrm{~mm}$ $\mathrm{Hg}$ during either axitinib or sunitinib treatment $[5,28]$. In study with sunitinib, Rini et al. [5] demonstrated that patients with hypertension defined by maximum systolic $\mathrm{BP} \geq 140 \mathrm{~mm} \mathrm{Hg}$ had significantly longer survival parameters of both PFS and overall survival. Bono et al. [4] showed that persistent $\mathrm{BP}>150 / 100 \mathrm{~mm} \mathrm{Hg}$ or BP requiring intensification of preexisting antihypertensive medication are the positive predictive factors in patients treated with sunitinib. 
It is a very interesting clinical finding that patients with hypertension induced by sorafenib and those with preexisting hypertension have a longer PFS. Perhaps it can be explained by the hypothesis that the history of hypertension correlates with higher gene expression of pathways associated with VEGFR 2\&3, PDGFR $\beta$, c-Kit, FLT3, RAF1 and BRAF, and other molecular factors which are unknown to us at the present time. All may be defined in patients with a higher probability of clinical benefit during sorafenib treatment.

It is discussed that concomitant cardiovascular medications may improve the outcome of oncologic patients. There is evidence that long-term use of angiotensin system inhibitors may protect against cancer [29]. Patients with metastatic renal carcinoma treated with sunitinib and hypertension controlled by angiotensin-converting enzyme inhibitors or angiotensin II receptor blockers have longer PFS and overall survival [30]. The experimental data showed that statins may increase cytostatic/ cytotoxic effects of sorafenib (but not sunitinib) [31]. Cardiovascular diseases coexist with diabetes or metabolic syndrome. Preclinical data have demonstrated that one of the anti-hyperglycemic drugs, metformin, has anticancer activity $[32,33]$. The role of other medicines (e.g. $\beta$-blockers like carvedilol or nebivolol) is unknown. In our study, patients with cardiovascular comorbidities were treated in line with obligatory guidelines of the European Society of Cardiology. Patients with hypertension received angiotensin-converting enzyme inhibitors and it could improve their outcome. Moreover, most patients with coronary artery disease or mild heart failure and many patients with hypertension were treated with statins (data not shown). There were patients who received metformin due to coexisting diabetes (data not shown). Only randomized prospective controlled trials can test the hypothesis of the positive relationship between cardiovascular medicines and outcomes of patients treated with angiogenesis inhibitors.

In conclusion, sorafenib-induced hypertension is a positive predictive factor in mRCC patients treated with sorafenib, especially in patients with a history of hypertension. The risk of cardiovascular complications is insignificant, even in patients with cardiologic comorbidities.

\section{References}

1 Ravaud A, Sire M: Arterial hypertension and clinical benefit of sunitinib, sorafenib and bevacizumab in first- and second-line treatment of metastatic renal cell cancer. Ann Oncol 2009;20:966-967.

-2 Azad NS, Posadas EM, Kwitkowski VE, Steinberg SM, Jain L, Annunziata CM, Minasian L, Sarosy G, Kotz HL, Premkumar A, Cao L, McNally D, Chow C, Chen HX, Wright JJ, Figg WD, Kohn EC: Combination targeted therapy with sorafenib and bevacizumab results in enhanced toxicity and antitumor activity. J Clin Oncol 2008;26:37093714.

-3 Rixe O, Billemont B, Izzedine H: Hypertension as a predictive factor of sunitinib activity. Ann Oncol 2007; 18:1117.

4 Bono P, Rautiola J, Utriainen T, Joensuu H: Hypertension as predictor of sunitinib treatment outcome in metastatic renal cell carcinoma. Acta Oncol 2011;50:569-573.

5 Rini BI, Cohen DP, Lu DR, Chen I, Hariharan S, Gore ME, Figlin RA, Baum MS, Motzer RJ: Hypertension as a biomarker of efficacy in patients with metastatic renal cell carcinoma treated with sunitinib. J Natl Cancer Inst 2011;103:763-773.
-6 Szmit S, Langiewicz P, Żołnierek J, Nurzyński P, Zaborowska M, Filipiak KJ, Opolski G, Szczylik C: Hypertension as a predictive factor for survival outcomes in patients with metastatic renal cell carcinoma treated with sunitinib after progression on cytokines. Kidney Blood Press Res 2011;35:18-25.

7 Khakoo AY, Kassiotis CM, Tannir N, Plana JC, Halushka M, Bickford C, Trent J 2nd, Champion JC, Durand JB, Lenihan DJ: Heart failure associated with sunitinib malate: a multitargeted receptor tyrosine kinase inhibitor. Cancer 2008;112: 2500-2508.

$\checkmark 8$ Di Lorenzo G, Autorino R, Bruni G, Cartenì G, Ricevuto E, Tudini M, Ficorella C, Romano C, Aieta M, Giordano A, Giuliano M, Gonnella A, De Nunzio C, Rizzo M, Montesarchio V, Ewer M, De Placido S: Cardiovascular toxicity following sunitinib therapy in metastatic renal cell carcinoma: a multicenter analysis. Ann Oncol 2009;20:15351542.

-9 Escudier B, Eisen T, Stadler WM, Szczylik C, Oudard S, Siebels M, Negrier S, Chevreau C, Solska E, Desai AA, Rolland F, Demkow T, Hutson TE, Gore M, Freeman S, Schwartz B, Shan M, Simantov R, Bukowski RM, TARGET Study Group: Sorafenib in advanced clear-cell renal-cell carcinoma. N Engl J Med 2007;356:125-134.
10 Eskens FA, Verweij J: The clinical toxicity profile of vascular endothelial growth factor (VEGF) and vascular endothelial growth factor receptor (VEGFR) targeting angiogenesis inhibitors: a review. Eur J Cancer 2006;42:3127-3139.

-11 Extermann M: Interaction between comorbidity and cancer. Cancer Control 2007;14: 13-22.

-12 Staehler M, Haseke N, Stadler T, Bader M Karl A, Becker A, Stief CG: Renal surgery in the elderly: morbidity in patients aged $>75$ years in a contemporary series. BJU Int 2008; 102:684-687.

13 He J, Ogden LG, Bazzano LA, Vupputuri S, Loria C, Whelton PK: Risk factors for congestive heart failure in US men and women: NHANES-I epidemiologic follow-up study. Arch Intern Med 2001;161:996-1002.

14 Levy D, Larson MG, Vasan RS, Kannel WB, Ho KK: The progression from hypertension to congestive heart failure. JAMA 1996;275: 1557-1562.

15 Tolcher AW, Appleman LJ, Shapiro GI, Mita AC, Cihon F, Mazzu A, Sundaresan PR: A phase I open-label study evaluating the cardiovascular safety of sorafenib in patients with advanced cancer. Cancer Chemother Pharmacol 2011;67:751-764. 
-16 Chu TF, Rupnick MA, Kerkela R, Dallabrida SM, Zurakowski D, Nguyen L, Woulfe K, Pravda E, Cassiola F, Desai J, George S, Morgan JA, Harris DM, Ismail NS, Chen JH, Schoen FJ, Van den Abbeele AD, Demetri GD, Force T, Chen MH: Cardiotoxicity associated with tyrosine kinase inhibitor sunitinib. Lancet 2007;370:2011-2019.

-17 Telli ML, Witteles RM, Fisher GA, Srinivas S: Cardiotoxicity associated with the cancer therapeutic agent sunitinib malate. Ann Oncol 2008;19:1613-1618.

18 Kamada P, Dudek AZ: Sorafenib therapy for metastatic renal carcinoma in patients with low cardiac ejection fraction: report of two cases and literature review. Cancer Invest 2010;28:501-504.

19 Wong MK, Jarkowski A: Response to sorafenib after sunitinib-induced acute heart failure in a patient with metastatic renal cell carcinoma: case report and review of the literature. Pharmacotherapy 2009;29: 473-478.

-20 Schmidinger M, Zielinski CC, Vogl UM, Bojic A, Bojic M, Schukro C, Ruhsam M, Hejna $\mathrm{M}$, Schmidinger $\mathrm{H}$ : Cardiac toxicity of sunitinib and sorafenib in patients with metastatic renal cell carcinoma. J Clin Oncol 2008;26:5204-5212.

21 Weikert S, Boeing H, Pischon T, Weikert C, Olsen A, Tjonneland A, Overvad K, Becker N, Linseisen J, Trichopoulou A, Mountokalakis T, Trichopoulos D, Sieri S, Palli D, Vineis P, Panico S, Peeters PH, Bueno-de-Mesquita HB, Verschuren WM, Ljungberg B, Hallmans G, Berglund G, González CA, Dorronsoro M, Barricarte A, Tormo MJ, Allen N, Roddam A,
Bingham S, Khaw KT, Rinaldi S, Ferrari P, Norat T, Riboli E: Blood pressure and risk of renal cell carcinoma in the European prospective investigation into cancer and nutrition. Am J Epidemiol 2008;167:438-446.

22 Zhu X, Stergiopoulos K, Wu S: Risk of hypertension and renal dysfunction with an angiogenesis inhibitor sunitinib: systematic review and meta-analysis. Acta Oncol 2009;48: 9-17.

23 Wu S, Chen JJ, Kudelka A, Lu J, Zhu X: Incidence and risk of hypertension with sorafenib in patients with cancer: a systematic review and meta-analysis. Lancet Oncol 2008;9: 117-123.

24 Bamias A, Lainakis G, Manios E, Koroboki E, Gyftaki R, Zakopoulos N, Dimopoulos MA: Diagnosis and management of hypertension in advanced renal cell carcinoma: prospective evaluation of an algorithm in patients treated with sunitinib. J Chemother 2009;21:347-350.

25 Maitland ML, Kasza KE, Karrison T, Moshier K, Sit L, Black HR, Undevia SD, Stadler WM, Elliott WJ, Ratain MJ: Ambulatory monitoring detects sorafenib-induced blood pressure elevations on the first day of treatment. Clin Cancer Res 2009;15:62506257.

26 Sane DC, Anton L, Brosnihan KB: Angiogenic growth factors and hypertension. Angiogenesis 2004;7:193-201.

27 Maitland ML, Moshier K, Imperial J, Kasza KE, Karrison T, Elliott W, et al: Blood pressure as a biomarker for sorafenib, an inhibitor of the VEGF signaling pathway. J Clin Oncol 2006;24(suppl):87, abstr 2035.
28 Rini BI, Schiller JH, Fruehauf JP, Cohen EE, Tarazi JC, Rosbrook B, Bair AH, Ricart AD, Olszanski AJ, Letrent KJ, Kim S, Rixe O: Diastolic blood pressure as a biomarker of axitinib efficacy in solid tumors. Clin Cancer Res 2011;17:3841-3849.

29 Lever AF, Hole DJ, Gillis CR, McCallum IR, McInnes GT, MacKinnon PL, Meredith PA, Murray LS, Reid JL, Robertson JW: Do inhibitors of angiotensin-I-converting enzyme protect against risk of cancer? Lancet 1998; 352:179-184.

30 Keizman D, Huang P, Eisenberger MA, Pili $\mathrm{R}$, Kim JJ, Antonarakis ES, Hammers $\mathrm{H}$, Carducci MA: Angiotensin system inhibitors and outcome of sunitinib treatment in patients with metastatic renal cell carcinoma: a retrospective examination. Eur J Cancer 2011;47:1955-1961.

31 Bil J, Zapala L, Nowis D, Jakobisiak M, Golab J: Statins potentiate cytostatic/cytotoxic activity of sorafenib but not sunitinib against tumor cell lines in vitro. Cancer Lett 2010; 288:57-67.

32 Ben Sahra I, Le Marchand-Brustel Y, Tanti JF, Bost F: Metformin in cancer therapy: a new perspective for an old antidiabetic drug? Mol Cancer Ther 2010;9:1092-1099.

-33 Guppy A, Jamal-Hanjani M, Pickering L: Anticancer effects of metformin and its potential use as a therapeutic agent for breast cancer. Future Oncol 2011;7:727-736. 